\title{
A Design of MATLAB Web-Based Interface for Power System Analysis
}

\author{
Ahmet ÇIFCİ ${ }^{1}$, Muhammer İLKUÇAR ${ }^{2}$, Yılmaz UYAROĞLU ${ }^{3}$ \\ ${ }^{l}$ Department of Electrical-Electronics Engineering, Mehmet Akif Ersoy University, Burdur-TURKEY \\ ${ }^{2}$ Department of Computer Technology, Mehmet Akif Ersoy University, Burdur-TURKEY \\ ${ }^{3}$ Department of Electrical-Electronics Engineering, Sakarya University, Sakarya-TURKEY
}

*Corresponding Author: Ahmet ÇIFCI, Department of Electrical- Electronics Engineering, Mehmet Akif Ersoy University, Burdur-TURKEY

\begin{abstract}
In recent years, a great deal of attention has been received on the stability of electric power systems. A considerable amount of literature has been published on the stability of electric power systems. Lyapunov has defined a function which will install relationship between accumulated energy in the system and the dynamics of the system. This function is given by considering the concept of energy. If a system's energy is continuously decreasing until an equilibrium state is reached, the system is stable. If the total energy of a system is continuously decreased, the time derivative of energy function is negative definite. In this paper, we have presented a web-based interface for energy function analysis of two-machine infinite-bus power system. MATLAB Builder NE with WebFigures and ASP.NET platform has been used to design the web-based interface. Users can easily access and use interactive web-based simulation page for energy function analysis and also users can be analyzed the studied power system without constructing a candidate Lyapunov function. The estimate of stability regions (domain of attraction) are visualized for two-machine infinite-bus system with this web-based interface.
\end{abstract}

Keywords: Energy Function, MATLAB, Power System Analysis, Web-Based Interface

\section{INTRODUCTION}

An electric power system has become massively complex and dynamic. At the same time, power system stability problems have become apparent. In general, the electric power system is expressed with nonlinear dynamical equations including of system parameters. Any change in any parameter of the system could affect the behavior of nonlinear dynamical system. Hence, the system parameter variations can cause system instability. Many researchers have tried to solve this problem [1-5].

Power systems analysis is a difficult task which has been challenging engineers. Several researchers have developed various attractive software packages to aid to the power system analysis. One of them is MATLAB [6] software package, which has become more and more popular for both research and educational purposes because of its important features [7]. In the last decades, several application programs have been transferred to the web-based platform. Ong and Gooi [8] described a prototype software package that includes a web-based Power Flow Simulator and a java-based Graphical User Interface (GUI) as a simulation environment for power system analysis and educational purposes via the Internet. In [9], Chen and Lu demonstrated an attempt to create a web-based, platformindependent power system simulation environment. A flexible architecture of a web-based tool has been proposed to serve as a platform for power system visualization with open data structures by $\mathrm{Li}$ in [10]. In [11], where authors presented the development of an educational web-based power flow simulator. They concluded that the simulator is used to teach the power flow of the power system in undergraduate courses. Colak et al. [12] developed a web-based laboratory for DC motors experiments in order to improve learning abilities of students and researchers in real-world applications on the Internet. Uyaroglu and Varan [13] analyzed a power system using MATLAB web figure control tool through web platform for teaching the relations between chaotic nonlinear dynamics and power system stability phenomena. An analysis of nonlinear systems with a web-based interface has been studied by Kacar and Cankaya in [14]. 
In our previous work we have analyzed two-machine infinite-bus power system by applying Lyapunov (energy) function based on Lyapunov's second method [15]. The method is a powerful tool for analysis of power systems. However, there is currently no general method for constructing Lyapunov function. We have used the variable gradient method which arises from Lyapunov's second method. In this paper, we have presented a web-based interface for energy function analysis of two-machine infinite-bus power system. MATLAB Builder NE with WebFigures and ASP.NET platform has been used to design the web-based interface. Users can easily access and use interactive web-based simulation page for energy function analysis. Users can be analyzed the studied power system without constructing a candidate Lyapunov function.

The paper organized as follows. Firstly, the mathematical model of the two-machine infinite-bus power system is presented. The studied power system's energy function also is given. More, the main idea of MATLAB builder NE and MATLAB web figure are introduced. Finally, the web-based interface is designed and some useful conclusions are obtained.

\section{Mathematical Model of THE System}

We consider the power system model shown in Figure 1, which is taken from [16].

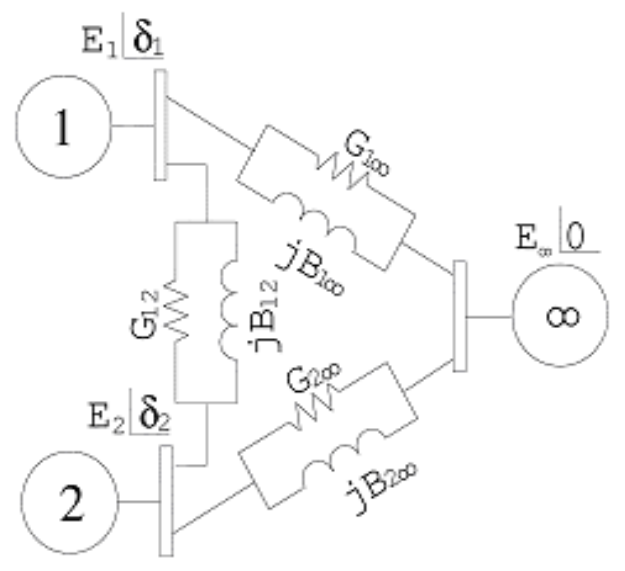

Figure1. Power system model [16]

The two-machine infinite-bus power system can be mathematically described by the following pair of differential equations [16]:

$$
\begin{aligned}
& \dot{\delta}_{1}=\omega_{1} \\
& \mathrm{M}_{1} \dot{\omega}_{1}=-\mathrm{T}_{1} \omega_{1}+\mathrm{P}_{1}-\mathrm{C}_{1} \sin \delta_{1}-\mathrm{D}_{1} \cos \delta_{1}-\mathrm{C}_{12} \sin \left(\delta_{1}-\delta_{2}\right) \\
& -\mathrm{D}_{12} \cos \left(\delta_{1}-\delta_{2}\right) \\
& \dot{\delta}_{2}=\omega_{2} \\
& \mathrm{M}_{2} \dot{\omega}_{2}=-\mathrm{T}_{2} \omega_{2}+\mathrm{P}_{2}-\mathrm{C}_{2} \sin \delta_{2}-\mathrm{D}_{2} \cos \delta_{2}-\mathrm{C}_{12} \sin \left(\delta_{2}-\delta_{1}\right) \\
& -\mathrm{D}_{12} \cos \left(\delta_{2}-\delta_{1}\right)
\end{aligned}
$$

The two-machine infinite-bus power system's energy function can be given by the following equation, for more details see [15].

$$
\begin{aligned}
& \mathrm{V}\left(\delta_{1}, \omega_{1}, \delta_{2}, \omega_{2}\right)=\mathrm{D}_{1} \sin \delta_{1}-\mathrm{C}_{12}\left(\cos \left(\delta_{1}-\delta_{2}\right)-\cos \delta_{2}\right)-\mathrm{C}_{1}\left(\cos \delta_{1}-1\right)-\mathrm{P}_{1} \delta_{1} \\
& +\mathrm{D}_{12}\left(\sin \left(\delta_{1}-\delta_{2}\right)+\sin \delta_{2}\right)-\frac{1}{2} \mathrm{M}_{1} \omega_{1}^{2}+\mathrm{D}_{2} \sin \delta_{2}-\mathrm{C}_{12}\left(\cos \left(\delta_{1}-\delta_{2}\right)-\cos \delta_{1}\right) \\
& -\mathrm{D}_{12}\left(\sin \left(\delta_{1}-\delta_{2}\right)-\sin \delta_{1}\right)-\mathrm{C}_{2}\left(\cos \delta_{2}-1\right)-\mathrm{P}_{2} \delta_{2}-\frac{1}{2} \mathrm{M}_{2} \omega_{2}{ }^{2}
\end{aligned}
$$

\section{MATLAB BUILDER AND MATLAB WEB Figure}

In The MATLAB builder NE which is an additional product of MATLAB compiler enables you to create applications using MATLAB and then deploys them as components in .NET and COM environments. .NET and COM components can now be used in your own .NET application, 
separately from MATLAB. MATLAB Builder NE encrypts certain MATLAB programs and then generates .NET or COM wrappers around them so that they can be accessed just like native .NET and COM components with the use of MATLAB compiler [17, 18].

The Web Figures feature provided by MATLAB builder NE is used in order to illustrate MATLAB figures in Internet pages and make graphical manipulation such as zooming, rotating and panning [18].

\section{DESIGN OF THE WEB-BASED INTERFACE}

The system architecture is shown in Figure 2. There are MATLAB builder NE with Web Figures and .NET technology on the server. Hence, there is also no need to install MATLAB Compiler Runtime (MCR). Server responds the client requests through web browser. The clients see the responses on the screen. The clients can make graphical manipulation such as zooming in or out, rotating and panning on their own web browser via MATLAB web figure. The clients access via a web browser (Internet Explorer, Opera, Firefox or Google Chrome) from a PC, laptop, PDA or smart phone. The flow chart of the system is outlined in Figure 3. The process of using deployment tool is presented in Figure 4.

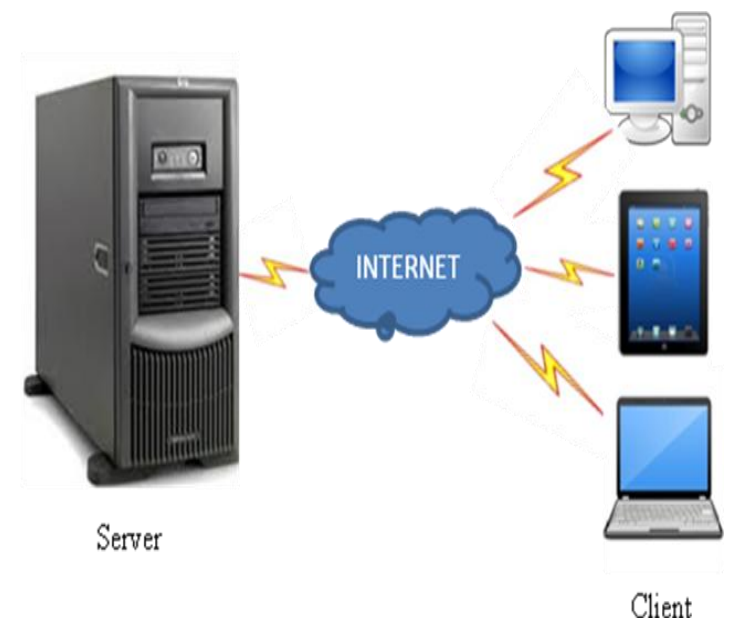

Figure2. The system architecture

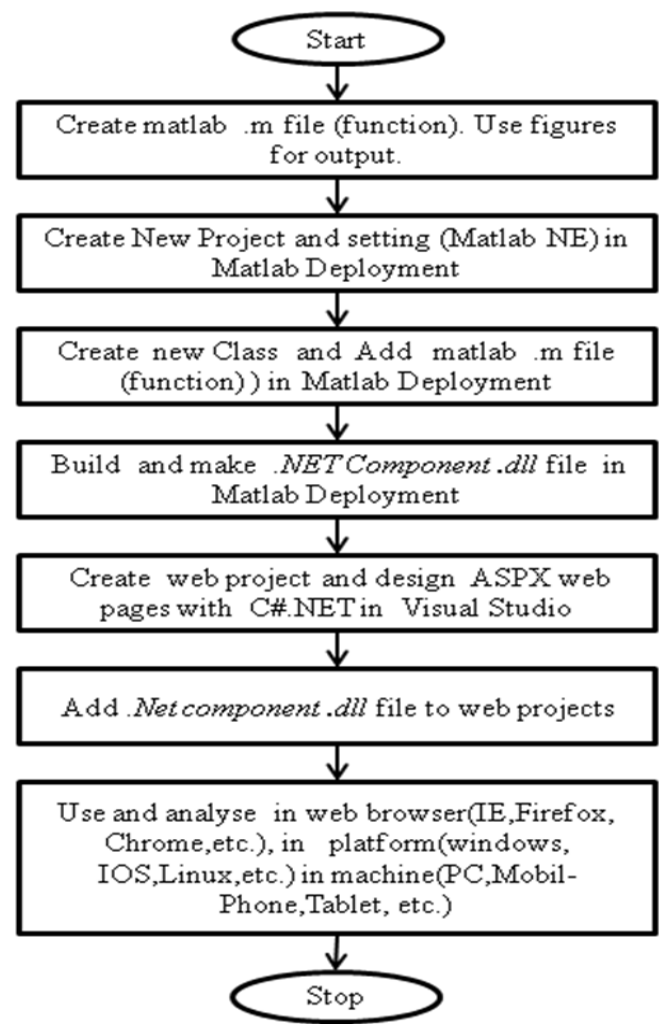

Figure3. The flow chart of the system 


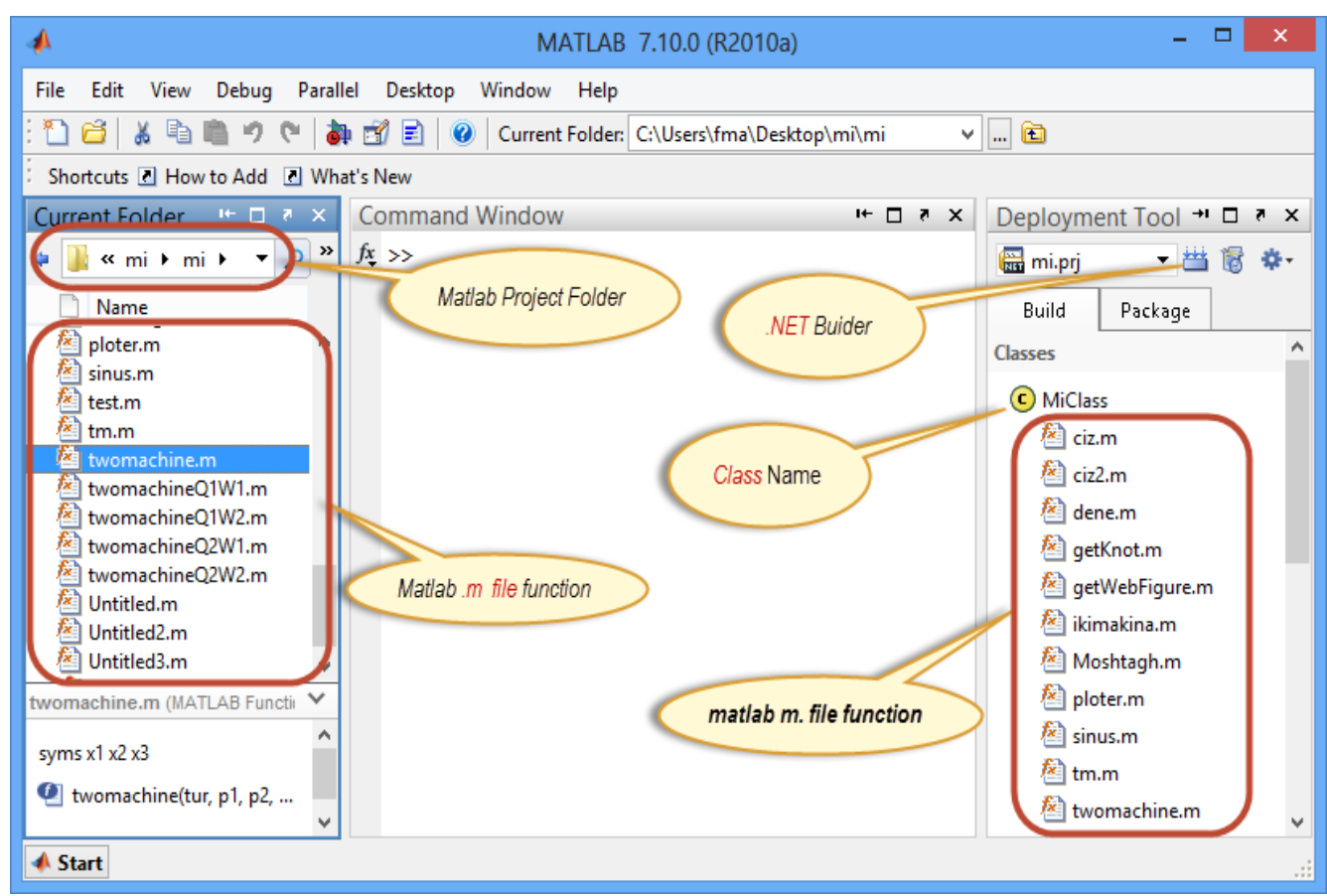

Figure4. MATLAB screen

The . $m$ file is composed and then the output of the function is saved as web figure as shown below.

function output $=$ My Function (param)

fig = figure;

$\cdots$

output = web figure(fig);

close(fig);

end

A new project is constituted from the deployment tool window (Figure 5 (1)). The name of the project (Figure $6(1)$ ), the physical location of the project (Figure $6(2)$ ) and the target of the project (Figure 6 (3)) is determined and then MATLAB builder NE project is started.

The project that was created earlier can be recast with Settings option (Figure 5 (2)) and (1), (2), (3) in Figure 6 if necessary.

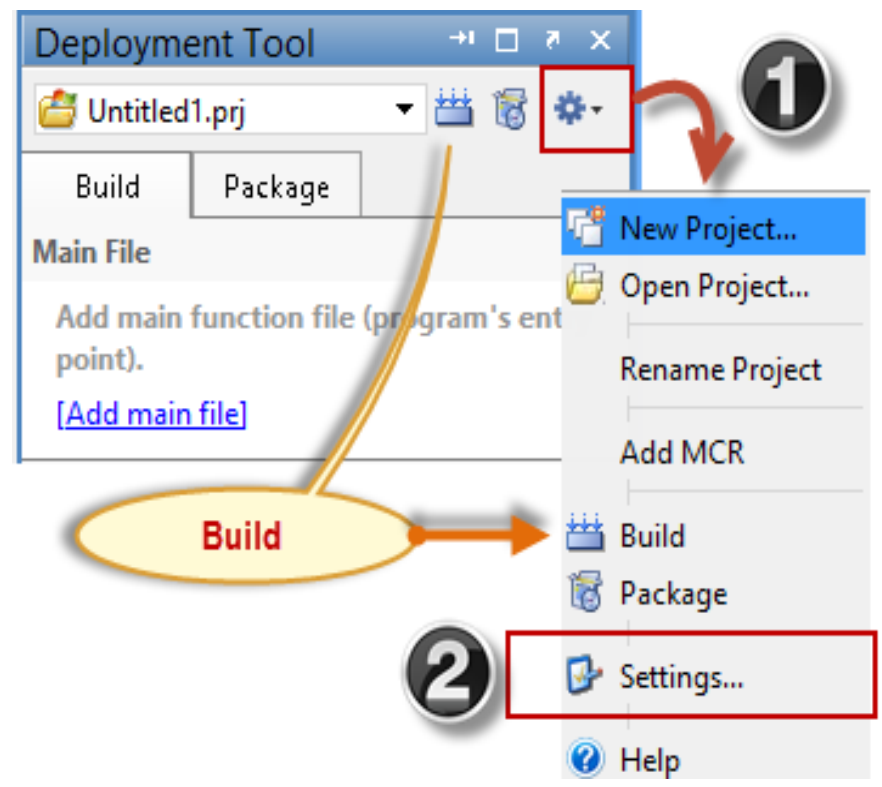

Figure5. The deployment tool 


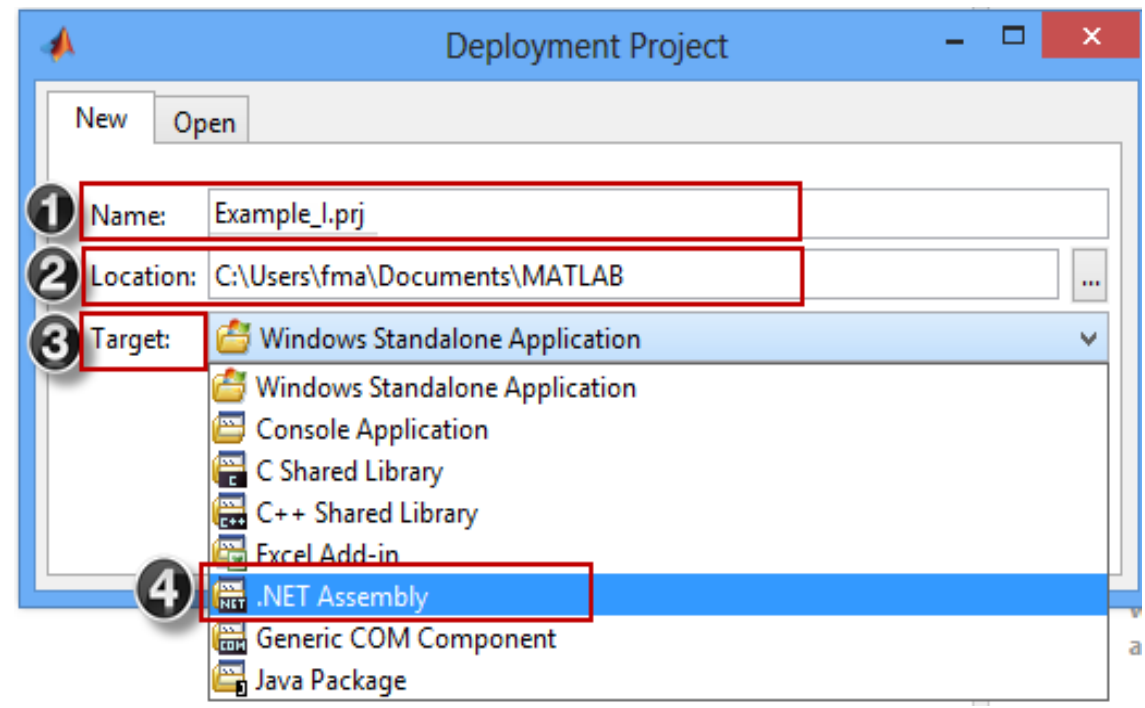

Figure6. MATLAB deployment project settings

After the project is created, a class is constituted using ASPX and C\# .NET. So then users can click on Add Class link as shown in Figure 7 and can give an appropriate class name as shown in Figure 8. Then, when writing the C\#.NET code for ASPX, this class name will be called as shown below.

using MathWorks.MATLAB.NET.WebFigures;

using MathWorks.MATLAB.NET.Arrays;

using Example_I; //MATLAB Deployment Project Name

public partial class_Default : System.Web.UI.Page

\{

protected void Page_Load(object sender, EventArgs e)

\{

MWCharArray param1 $=$ TextBox1.Text;

Example_I.Class1 MyExp = new Class1();

WebFigureControll.WebFigure $=$ new WebFigure( MyExp.MyFunction (paraml));

\}

\}

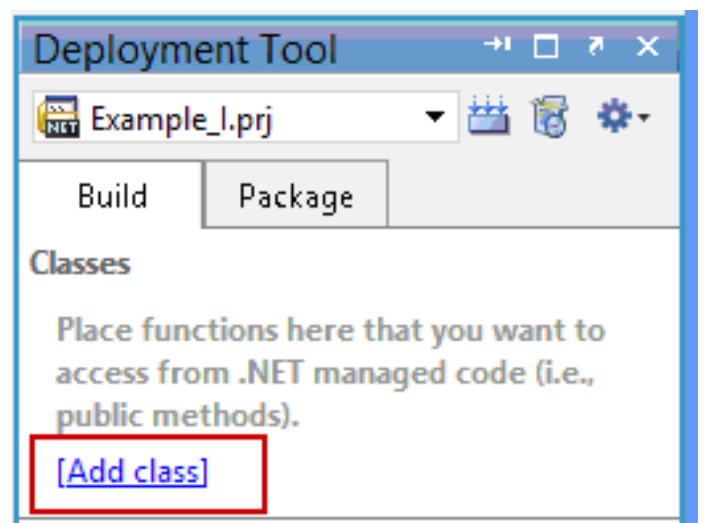

Figure7. Adding class

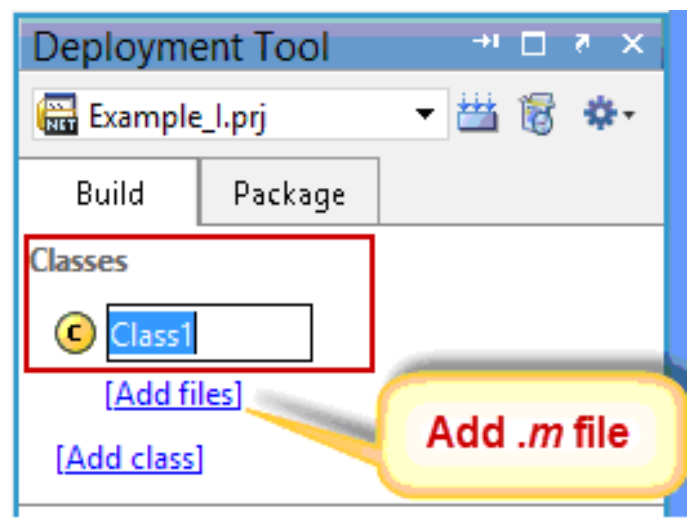

Figure8. Giving class name

In the next step, the.$m$ file is defined in order to constitute the .Net component with the.$d l l$ extension. After a right-click with the mouse (Figure 9 (1)) and a click on Add Reference (Figure 9 (2)), the .dll file is added to web project as shown in Figure 10.

International Journal of Research Studies in Electrical and Electronics Engineering (IJRSEEE) Page | 63 


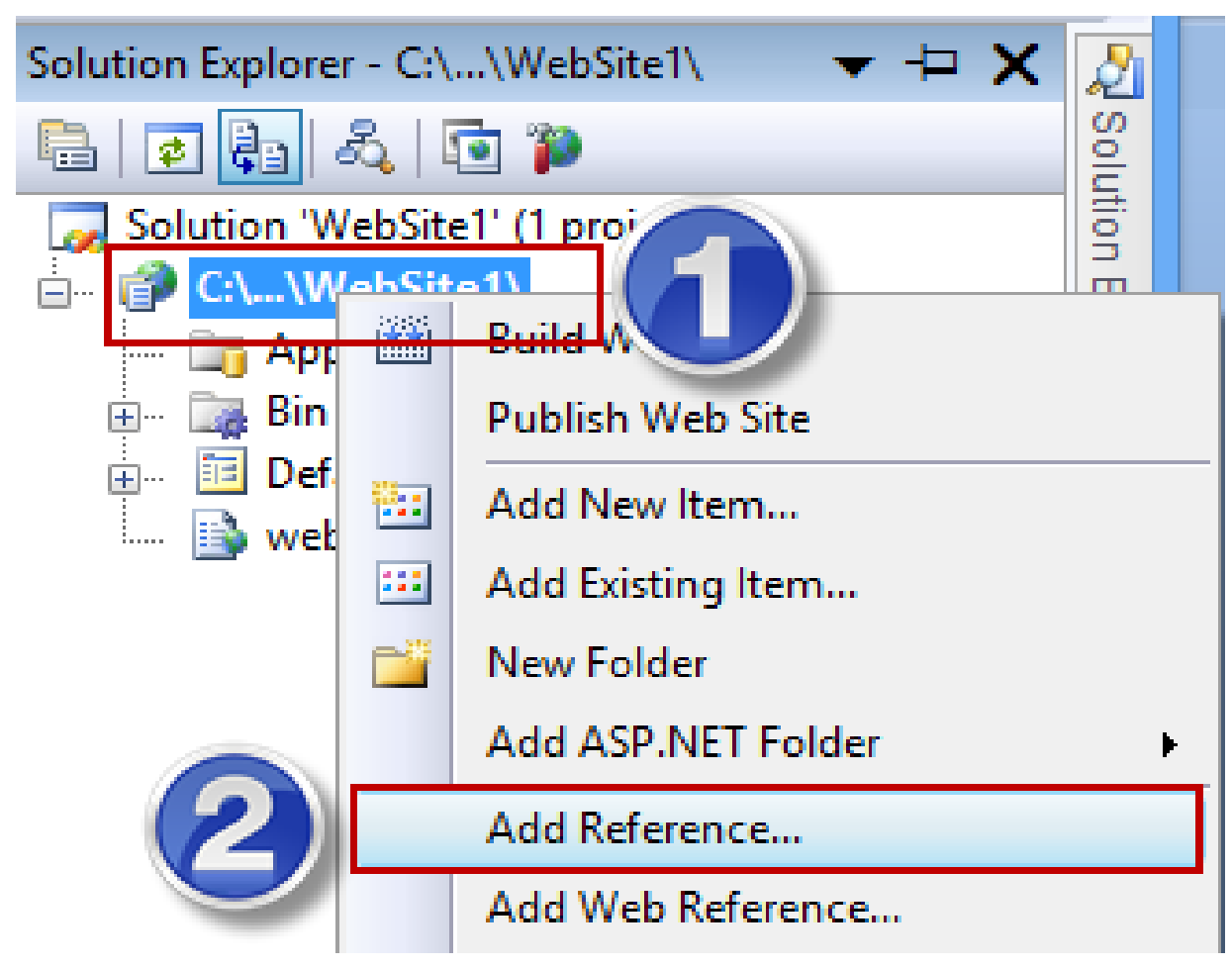

Figure9. Adding reference to web ASPX project

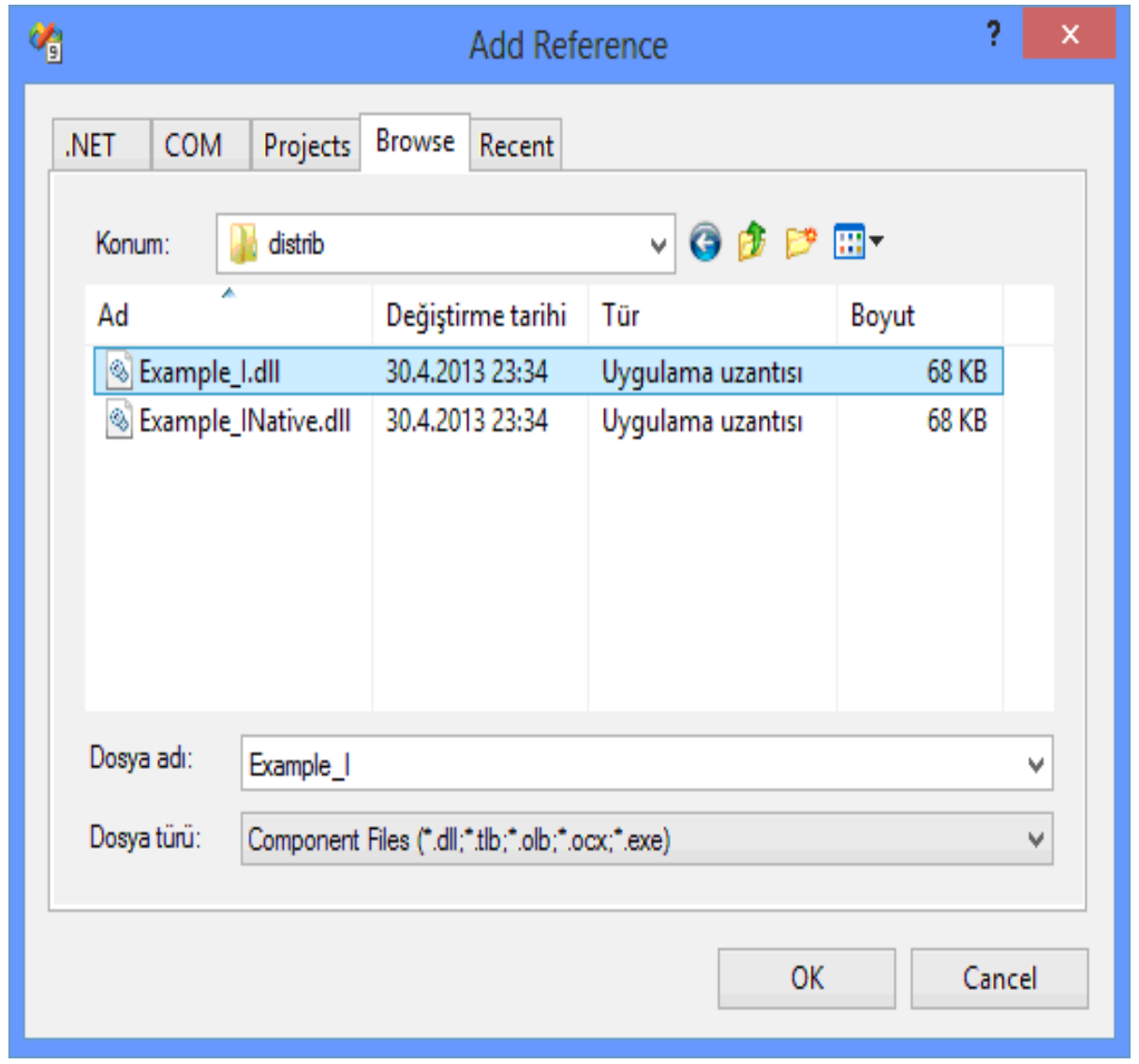

Figure10. Adding .dll file as a reference to ASPX project

After the preparation of the ASPX web project, the web interface is designed as shown in Figure 11. .dll file project must be given notice as using Example_ $I$; in order to use MATLAB functions in MATLAB builder NE .dll file on the web page.

The MWArray.dll file is added to the project as a reference for data type compatibility C\# .NET with MATLAB and using Math Works. MATLAB.NET. Arrays; notification should be made. 


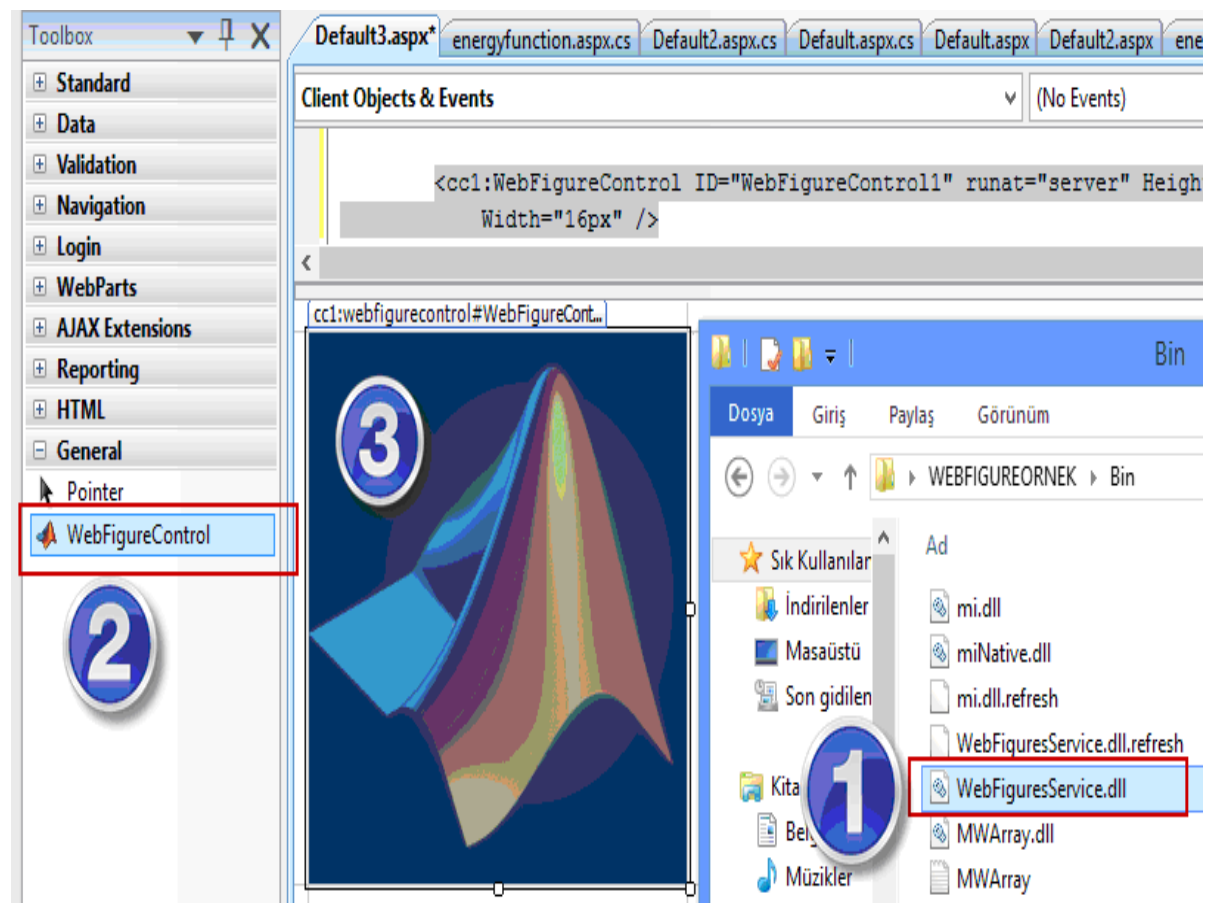

Figure11. Adding MATLAB WebFigureService to ASPX web project

To add MATLAB WebFigureService into ASPX web project, WebFigureService.dll file that comes with MATLAB builder NE is transferred to General tab in the Toolbox window of Visual Studio Editor Design section by using drag-and-drop (Figure 11 (1-2)). Then, WebFigureControl object in the Toolbox window is transferred to design screen by using drag-and-drop.

Users had to re-construct a new candidate Lyapunov function for varying values of power system in previous studies. It is a difficult, tiresome and time-consuming task for users. Figure 12 and 13 indicate that users can change the value of power system's variable what they want and they can plot power system's three and two dimensional graphs in a very short time. Figure 12 and 13 demonstrates the estimate of stability region by the energy function in (2). Also, they show the level curves of energy function.

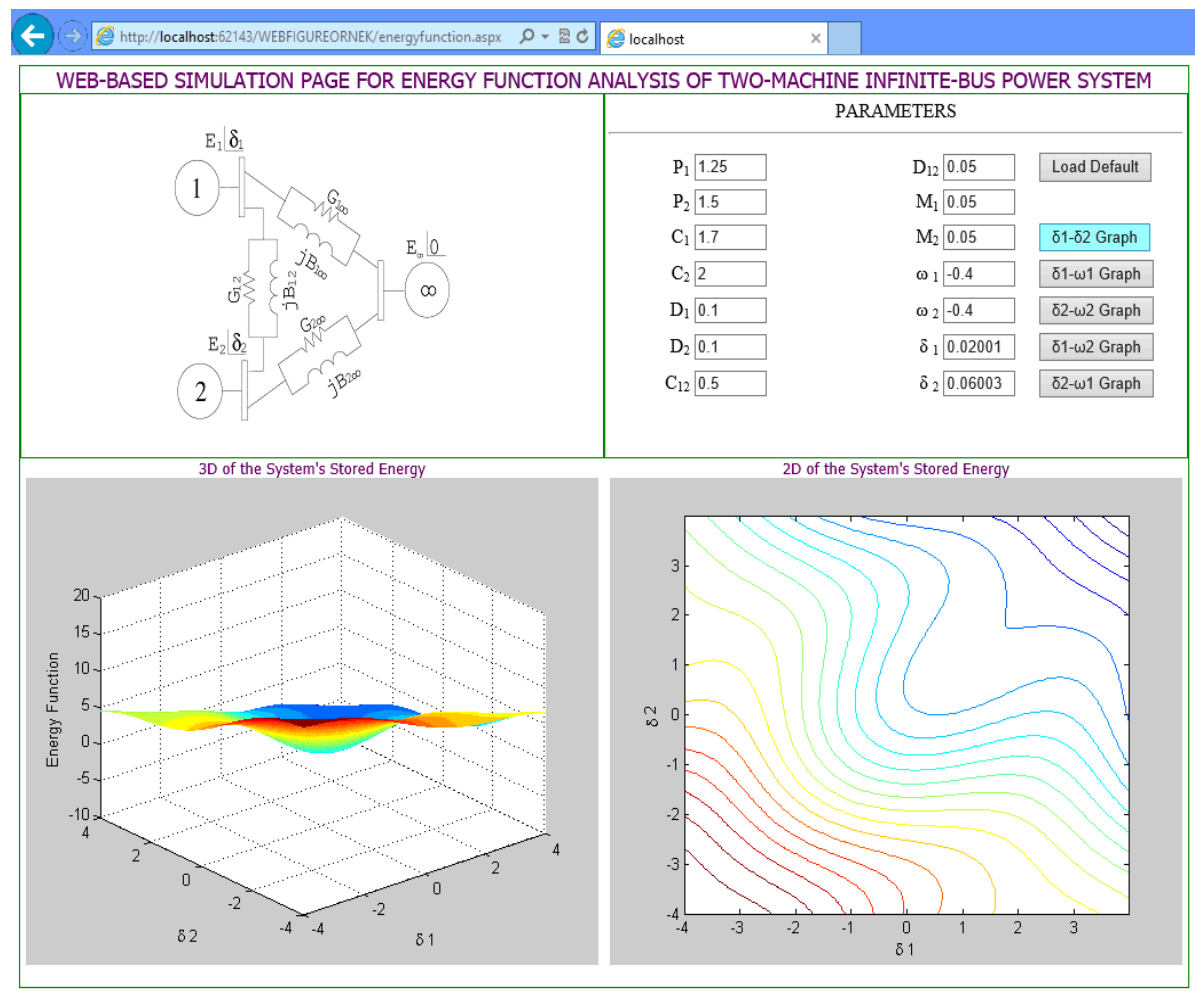

Figure13. $3 D$ and $2 D$ graph for $\delta_{1}-\delta_{2}$ 


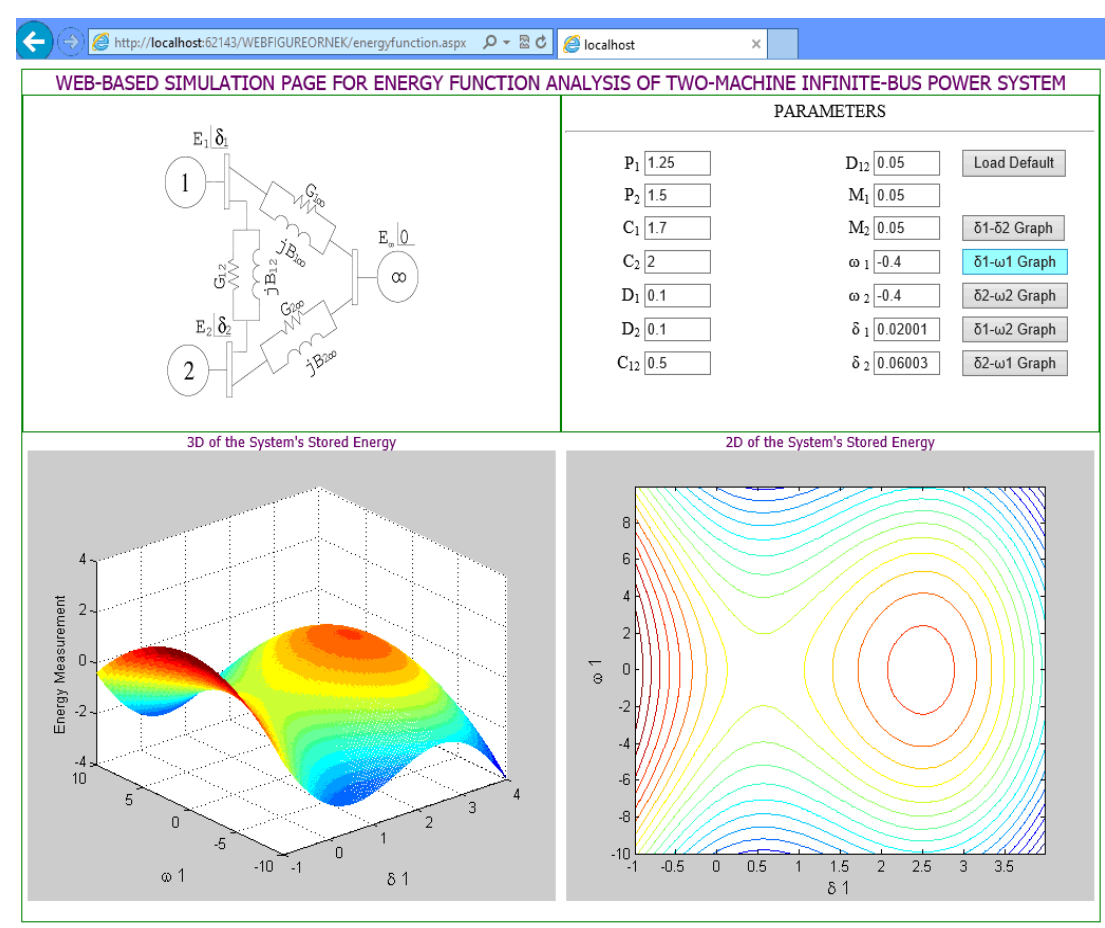

Figure14. $3 D$ and $2 D$ graph for $\delta_{1^{-}} \omega_{1}$

\section{CONCLuSiON}

A web-based interface using MATLAB Builder NE with WebFigures and ASP.NET platform for energy function analysis of two-machine infinite-bus power system is presented in this study. The advantages of the presented web-based interface can be written as follows:

- Users can easily and securely access the web-based simulation page from anywhere, at any time.

- Users can access via a web browser (Internet Explorer, Opera, Firefox or Google Chrome etc.) from a PC, laptop, PDA or smart phone etc.

- Users can use interactive web-based simulation page for energy function analysis.

- Users can be analyzed the studied power system without constructing a candidate Lyapunov function.

- Users can change the studied power system parameters.

- Users can visualize and manipulate 2D plots and 3D plots.

\section{REFERENCES}

[1] M. Larsson, "ObjectStab: An educational tool for power system stability studies," IEEE Trans. Power Syst. 2004; 19: 56-63.

[2] F. Milano, "An open source power system analysis toolbox," IEEE Trans. on Power Systems 2005; 20: 1199-1206.

[3] J. S. Patel, and M. N. Sinha, "Power system transient stability analysis using ETAP aoftware," National Conference on Recent Trends in Engineering \& Technology, 2011.

[4] A. Cifci, Y. Uyaroglu, and M. A. Yalcin, "Voltage Stability via Energy Function Analysis on Reduced Order Model of Power System," Turkish Journal of Electrical Engineering and Computer Science 2012; 20: 1031-1043.

[5] A. Mahmud, M. J. Hossain, H. R. Pota, "Effects of large dynamic loads on power system stability," Int J Electr Power Energy Syst.2013; 44:357-363.

[6] High-performance numeric computation and visualization software, The MathWorks, Inc.,Natick, MA., 2001.

[7] S. Ayasun, C. O. Nwankpa, and H. G. Kwatny, "Voltage stability toolbox for power system education and research," IEEE Trans. Educ. 2006; 49: 432-442.

[8] Y. S. Ong, and H. B. Gooi, "A web-based power flow simulator for power engineering education," IEEE Power Engineering Society Summer Meeting, pp. 1002-1007, 1999.

[9] S. Chen, F. Y. Lu, "Web-based simulations of power systems," IEEE Computer Applications in Power 2002; 15 : 35-40.

International Journal of Research Studies in Electrical and Electronics Engineering (IJRSEEE) Page | 66 
[10] F. Li, "Web tool opens up power system visualization," IEEE Power and Energy Magazine 2003; $37-41$.

[11] K. M. Yang, K. S. Lee, J. B. Park, and J. R. Shin, "The development of on educational web-based power flow simulator," in Proceeding of the International Conference on Electrical Engineering, Sapporo Convention Center, Sapporo, 2004.

[12] I. Colak, S. Demirbas, S. Sagiroglu, and E. Irmak, "A novel web-based laboratory for DC motor experiments," Computer Applications in Engineering Education 2011; 19: 125-135.

[13] Y. Uyaroglu, and M. Varan, "Web-based interface of chaotic swing dynamics in electric power systems," Scientific Research and Essays 2011; 6: 706-713.

[14] S. Kacar, and I. Cankaya, "Analysis of nonlinear systems using MATLAB and ASP.NET based web interface," Journal of the Faculty of Engineering and Architecture of Gazi University 2012; 27: 795-806. (in Turkish)

[15] A. Cifci, and Y. Uyaroglu, "Energy function analysis of a two-machine infinite-bus power system by Lyapunov's second method," Przegląd Elektrotechniczny Electrical Review 2012; 2: 270-27.

[16] L. F. C. Alberto, F. H. J. R. Silva, and N. G. Bretas, "Extended Lyapunov functions for power systems detailed models," in Proc. of 14th PSCC-Power System Computation Conference, Sevilla, 2002.

[17] MATLAB Builder NE User's Guide

[18] MATLAB Application Deployment Web Example Guide

\section{AUTHORS' BIOGRAPHY}

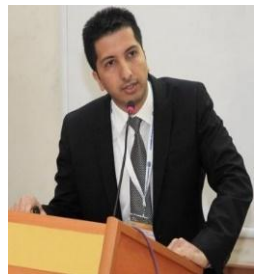

Ahmet Çifci, was born in Antakya, Turkey, on March 5, 1985. He received his B.Sc., M.Sc. and Ph.D. degrees in Electrical-Electronics Engineering from Sakarya University, Sakarya, Turkey, in 2007, 2011 and 2015, respectively.

$\mathrm{He}$ is an assistant professor in the Department of Electrical and Electronics Engineering at Mehmet AkifErsoy University and is the current Head of Department of Electrical and Electronics Engineering. He is also a Vice Dean of Bucak Faculty of Technology, Mehmet AkifErsoy University since 2016. He is interested in power systems, voltage stability, FACTS devices, electromagnetic field measurements and numerical computation techniques.

Dr. Çifciis a member of The Chamber of Electrical Engineers of Turkey.

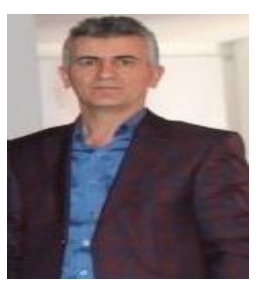

Muhammer İlkuçar, was born in Fethiye, Turkey, on January 1, 1970. He received the B.Sc. and the M.Sc. degrees in the Department of Electronics and Computer Education from Gazi University, Ankara, Turkey. He received a Ph.D. in Business Administration from Suleyman Demirel University in 2012.

He is an assistant professor in the Department of Computer Technology at Mehmet AkifErsoy University and is the current Head of Department of Computer Technology. He is interested in artificial neural networks, database mining, statistical learning algorithms, probability and machine learning.

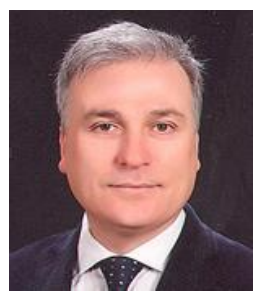

Yılmaz Uyaroğlu, was born in Sakarya, Turkey, on May 21, 1966. He received his B.Sc. in Electrical and Electronics Engineering from Istanbul Technical University, in 1989. 5 years period industrial working experience later, he received M.Sc. and $\mathrm{Ph} . \mathrm{D}$. degree in Electrical and Electronics Engineering from Sakarya University also postdoc at Hochschule fur Technik Zurich, in 1997, 2002, and 2006, respectively.

$\mathrm{He}$ is currently an associate professor in the department of Electrical and Electronics Engineering at Sakarya University. He is also a Vice Dean of Faculty of Engineering, Sakarya University. His research interests electrical power system quality, nonlinear systems and chaos, and chaotic synchronization for security communication.

Dr. Uyaroğluis a member of The Chamber of Electrical Engineers of Turkey.

Citation: Ahmet ÇİFCI et al. (2017). A Design of MATLAB Web-Based Interface for Power System Analysis, International Journal of Research Studies in Electrical and Electronics Engineering (IJRSEEE), 3(3), pp.59-67, DOI: http://dx.doi.org/10.204 31/2454-9436.0303005.

Copyright: (C) 2017 Ahmet ÇIFCİ. This is an open-access article distributed under the terms of the Creative Commons Attribution License, which permits unrestricted use, distribution, and reproduction in any medium, provided the original author and source are credited

International Journal of Research Studies in Electrical and Electronics Engineering (IJRSEEE) Page | 67 